\title{
Knowledge and provision practices of misoprostol among pharmacies in Senegal
}

\author{
Ramatoulaye Ndao \\ Nafissatou Diop \\ Population Council \\ Kate Reiss \\ Eva Burke
}

Follow this and additional works at: https://knowledgecommons.popcouncil.org/departments_sbsr-rh

Part of the Demography, Population, and Ecology Commons, Family, Life Course, and Society Commons, International Public Health Commons, Maternal and Child Health Commons, and the Women's Health Commons How does access to this work benefit you? Let us know!

\section{Recommended Citation}

Ndao, Ramatoulaye, Nafissatou Diop, Kate Reiss, and Eva Burke. 2015. "Knowledge and provision practices of misoprostol among pharmacies in Senegal," STEP UP Evidence Brief. Dakar: Marie Stopes International and Population Council. 


\section{Knowledge and provision of misoprostol in Senegal pharmacies}

\section{SUMMARY}

- Pharmacies are key service delivery points for many women in Senegal.

- Currently, the majority of pharmacy workers do not have the knowledge to safely provide misoprostol to clients or health providers.

- Pharmacy workers' knowledge of misoprostol needs to be strengthened.

- Further, the supply chain in Senegal needs to be strengthened to ensure access to all essential medications, including misoprostol.

STEP UP generates policy-relevant research to promote an evidencebased approach for improving access to family planning and safe abortion.

We work in Bangladesh, northern India, Ghana, Kenya, and Senegal.

Population Council Coordinating Partner

African Population and Health Research Center icddr.b

London School of Hygiene and Tropical Medicine

Marie Stopes International

Partners in Population and Development

\section{Funded by}

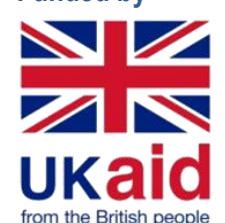

\section{INTRODUCTION}

Post-partum haemorrhage (PPH) and complications related to unsafe abortion are direct causes of maternal death in low- and middle-income countries; women, their families, and their communities all suffer as a result.

In Senegal, actions to eradicate this problem have made significant advances in recent years. However, there is much left to do -Senegal has not achieved Millennium Development Goal V, which called for the reduction of its maternal mortality ratio from 392 to 127 deaths per 100,000 births by 2015 .

In pursuit this goal, Marie Stopes International (MSI), and the Population Council conducted a study on the knowledge and practice of misoprostol provision among pharmacy workers, as part of the "Strengthening Evidence for Programming on Unintended Pregnancy" (STEP UP) research program.

This study is helping to guide strategies for expanding provision and proper delivery in pharmacies of misoprostol, a drug which is highly effective and acceptable for treating $\mathrm{PPH}$ and post-abortion complications.

Misoprostol is included on the List of Essential Medicines of the WHO and of Senegal.

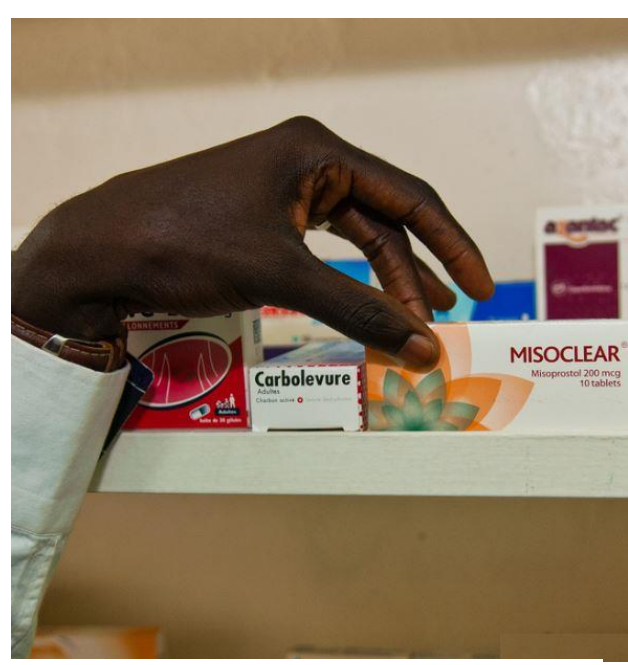

Photo credit: Marie Stopes International

\section{METHODOLOGY}

A survey was conducted among 110 pharmacy owners, managers, or employees in September 2013 to assess the knowledge, attitudes and practice on:
1) Availability of misoprostol;
2) Knowledge of misoprostol;
3) Reported misoprostol provision practices.

Fieldwork was conducted in September 2013. 


\section{RESULTS}

\section{Knowledge of Misoprostol}

Respondents were generally under-informed of the many uses of misoprostol.

- The majority $(75 \%)$ knew the product can be used to treat gastric ulcers but only $13 \%$ were aware it can be used for PAC.

- Knowledge of the drug's use in preventing and treating PPH was also low ( $1 \%$ and $4 \%$ respectively).

- Other gynaecological uses, such as cervical ripening $(3 \%)$ and treatment of intrauterine foetal deaths $(1 \%)$ were not well known either.

This lack of knowledge suggests that the full range of uses for misoprostol are not well-understood by pharmacy workers in Senegal. Education is needed to take advantage of the potential reduction in maternal mortality and morbidity that the product can deliver.

Another gap in knowledge related to side effects of the product.

- Only $14 \%$ cited dizziness and $13 \%$ bleeding as side effects.

- Almost half of the respondents $(47 \%)$ stated that they were unaware of the existence of any side effects of misoprostol.

Without this knowledge, pharmacy workers cannot appropriately counsel clients, raising potential health risks.

Furthermore, few respondents were aware of the proper dosages of misoprostol for specific conditions:

- $38 \%$ of pharmacy workers reported knowing the correct dosage for misoprostol as a treatment for gastric ulcers. Of these, only $83 \%$ were able to correctly identify the proper dosage of $800 \mathrm{mcg}$.

- $14 \%$ of respondents reported that they knew the proper dosage for PAC. Yet, only $4 \%$ of these respondents correctly stated a dosage of between 400 and $600 \mathrm{mcg}$.

- No respondents reported knowing the correct dosage for the prevention and treatment of PPH.

These results are concerning because without proper dosing, both the efficacy and the safety of misoprostol may be jeopardized.

Storage is also an important factor in drug efficacy. Generally, respondents had partial understanding of storage requirements. While $84 \%$ of them knew that misoprostol should be kept away from heat, only $28 \%$ were aware that it must also be kept away from humidity.
The full potential of misoprostol has not yet been realised in Senegal. With increased pharmacy worker education on the drug, important progress could rapidly be made in the reduction of maternal mortality and morbidity.

The lack of knowledge about misoprostol may be explained in part by the sources of information about the drug. Almost half $(45 \%)$ of respondents reported that they self-trained on the uses of the product through literature, brochures, etc. Others received information through medical delegates $(22 \%)$ and colleagues (20\%). Only $10 \%$ of respondents received information during university training. Other information sources included doctors, clients, television, and the internet.

Recognizing their lack of knowledge about the medication, $85 \%$ of respondents desired further support and training on misoprostol. Many stated that they needed information about all aspects of the product (58\%). More specific requests for information where about uses (37\%), side effects $(30 \%)$, complications (30\%), and dosage (28\%). Worryingly, even though respondents were not confident in their knowledge, they reported providing information to a range of providers, including midwives $(75 \%)$, gynaecologists $(42 \%)$, nurses $(33 \%)$, and general practitioners (17\%). This suggests the potential for diffusion of misinformation among medical professionals, and ultimately increased risk for patients.

Figure 1: Knowledge of misoprostol uses and registration

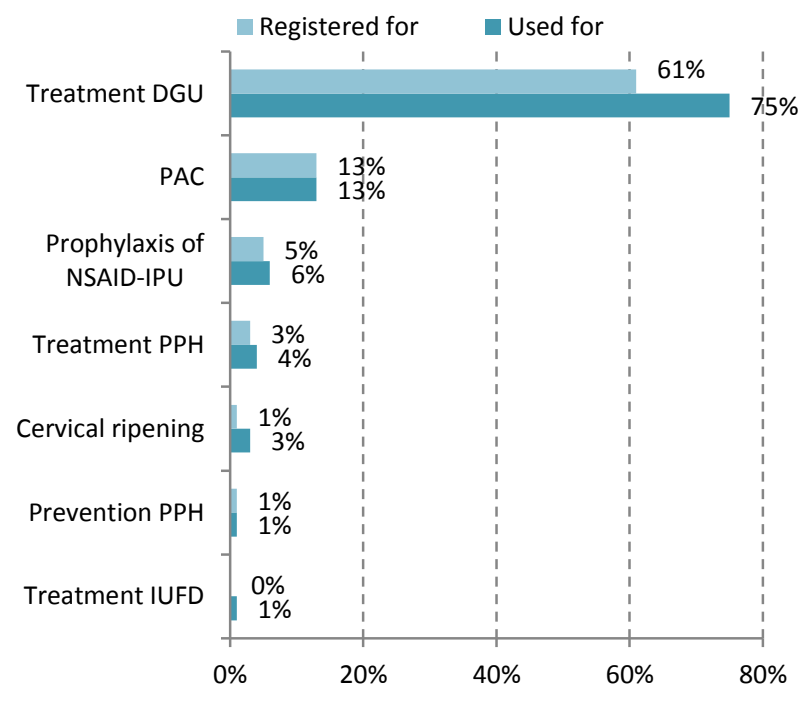

DGU: Duodenal or gastric ulcers IUFD: Intrauterine fetal death NSAID-IPU: NSAID-induced peptic ulcers 


\section{Provision of Misoprostol}

Twenty-seven (27) respondents reported selling misoprostol in their pharmacy ( $34 \%$ of the sample). However, $48 \%$ of those who were not selling the product did express the desire to do so.

The majority of sales were for the treatment of gastric ulcers, reported by $63 \%$ of carriers of misoprostol. An average of 58 tablets was sold per month per pharmacy for all indications. Pharmacy workers who reported that they do not sell misoprostol were asked to explain why. The main reasons are presented in Figure 2 (right).

The three brands of misoprostol available on the Senegalese market at the time of the study were: Arthrotec, Cytotec and Misoclear.

- Arthrotec was the most widely sold (in $56 \%$ of pharmacies that sold misoprostol). Arthrotec is a combination medicine with diclofenac that is registered for the treatment of gastric ulcers.

- Cytotec, also used to treat gastric ulcers, was available at $41 \%$ of pharmacies.

- And, finally, Misoclear, which has been registered for additional gynaecological uses such as PAC and PPH, was available at $19 \%$ of pharmacies.

Respondents reported that they decided on the types of misoprostol sold in their pharmacy based on what they know about the product's efficacy and availability in the supply chain. It will only be possible for misoprostol to contribute to a reduction in the maternal mortality ratio if there is increased knowledge of misoprostol's indications and increased availability of the product.

A fifth $(22 \%)$ of pharmacy workers reported that they had experienced clients asking for the medication without a prescription, but only one reported selling it in this situation.

The majority (78\%) of respondents believed that customers can afford the price of misoprostol, which is 9 USD per box for Arthrotec, 27 USD per box for Cytotec and 4 USD per box for Misoclear.

The majority of sales were for the treatment of gastric ulcers, reported by $63 \%$ of carriers of misoprostol. An average of 58 tablets was sold per month per pharmacy for all indications.
Figure 2: Reasons for not selling misoprostol

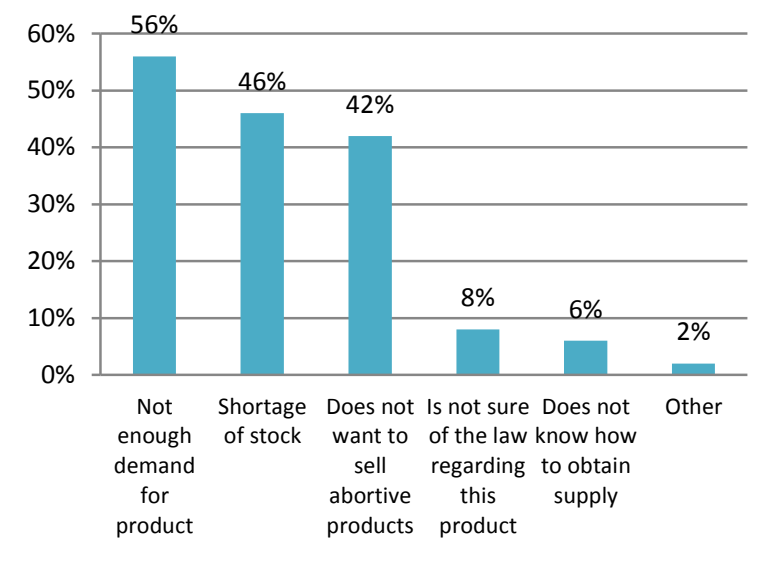

\section{DISCUSSION}

The pharmacy worker's role is vital for the health of the general population. As a contact point for the public, it is important that pharmacy workers have a good understanding and a proper supply of misoprostol.

A number of conclusions and recommendations can be drawn from this study. They can be grouped under the following categories:

\section{Increased communication:}

Even though the majority of pharmacy workers were aware of the use of misoprostol for gastric and duodenal ulcers, few knew of its gynecological applications. This suggests that the national approval of Misoclear for gynecological uses in 2011 has yet to be widely disseminated. To facilitate quicker diffusion of new policies and regulations, it is recommended that communication within the supply chain be strengthened, starting at the Pharmacy and Medicine Division of the Ministry of Health $(\mathrm{MoH})$. This includes the dissemination of the List of Essential Medicines by the $\mathrm{MoH}$, which will clarify the uses of misoprostol and has the potential to help de-stigmatize it.

\section{Increased education:}

The study revealed a general lack of knowledge regarding the proper dosage of misoprostol for all treatments. Additionally, almost half of respondents were unable to name any side effects at all. This is a potential risk for consumers. Many respondents expressed the need for further training on misoprostol and its usages, especially for gynecological purposes. It is recommended that training sessions for pharmaceutical personnel be implemented. 
Increased availability of misoprostol in pharmacies:

Despite willingness to provide misoprostol, a low percentage of pharmacy workers reported stocking misoprostol at the time of the study due to low demand and stock outs. Low demand for misoprostol may reflect low numbers of prescriptions by health providers. Further studies among health providers are needed to explore how to increase prescription and use of misoprostol in the fight against maternal morbidity and mortality.

Pharmacists and distributors have a key role to play in ensuring there is no stock out of the product, by responding effectively and continuously to demand. Recently, steps taken in Senegal to strengthen the supply chain have been successful in preventing stock outs of contraceptives. Similar efforts are required to strengthen the supply chain for other important medications for reducing maternal mortality such as misoprostol.

\section{CONCLUSION}

The Senegalese government has made significant efforts in the fight against maternal morbidity and mortality. However, at the time of the study, misoprostol was not yet widely available in the public health system.

Amplified communication about the product can contribute to an increase in demand from providers in all sectors. However, as demand for the product increases, the supply chain must be strengthened to respond effectively and avoid shortages.

The Ministry of Health has committed to working with the Order and Syndicate of Pharmacies to ensure the availability of essential medicines, including misoprostol, and to train pharmacy workers to allow them to sell misoprostol safely for gynaecological purposes. Misoprostol has a significant role to play in reducing maternal mortality, but it must be made more available at the points where people most commonly access the health system, including pharmacies.

\section{SUGGESTED READINGS}

Ndao, R., Mane, B., Burke, E., Diop, N., Reiss, K., Ngo, T., Footman., K, van Min, M., 2014, « Knowledge and provision practices of misoprostol among pharmacies in Senegal. STEP UP Research Report," Dakar, Marie Stopes International \& Population Council.

\section{KEY RECOMMENDATIONS}

- Strengthen communication between the Pharmacy and Medicine Division of the Ministry of Health and drug suppliers to facilitate quicker diffusion of new laws and regulations.

- Disseminate widely the List of Essential Medicines to health providers and pharmacy workers to increase knowledge, and decrease misconceptions, about priority drugs and their indications in the Senegalese context.

- Hold training sessions for pharmaceutical personnel to increase knowledge of medications on the List of Essential Medicines, in particular misoprostol.

- Increase the availability of misoprostol among drug distributors and in pharmacies to respond effectively to demand and avoid shortages.

- Conduct further studies about knowledge and uses of misoprostol among health providers, as they are able to prescribe misoprostol, to explore ways to increase prescription and uses.
Suggested citation: Ndao, R., Diop, N., Reiss, K., Burke, E., 2015, "Knowledge and provision practices of misoprostol among pharmacies in Senegal". STEP UP Evidence Brief. November 2015. Dakar: Marie Stnnes International \& Ponıluation Conıncil 